Journal of Education and Educational Development

8(1), 180-193, 2021

DOI: http://dx.doi.org/10.22555/joeed.v8i1.437

\title{
The Impact of Work-Family Conflict on Job and Life Satisfaction for Female Executive MBA Students
}

\author{
Urfi Khalid \\ Institute of Business Management, Pakistan
}

\begin{abstract}
The Work-Family Conflict (WFC) is an established phenomenon of modern economies and has become more intense for the female labor force which has to perform multiple roles in society. This study has been conducted to answer research questions regarding the impact of WFC on job satisfaction and its effect on life satisfaction of female executive students who are working as well as studying. The study's purpose is to identify areas of conflict for female students to enhance their qualification as future labor force and examine the association between WFC, job satisfaction, and life satisfaction. The study worked on three hypotheses along with data collected from a sample of 200 female Executive MBA students from four business universities in Karachi. The survey also included demographic questions information regarding age and marital status. The survey results report a negative correlation between WFC, job satisfaction, and life satisfaction.
\end{abstract}

Keywords: female executive MBA students, job satisfaction, life satisfaction, work-family conflict

\section{Introduction}

The buzzword of contemporary business economies is 'Work-Family Conflict' which occurs when there are conflicting demands in the roles of family and work, and fulfilling the two roles becomes difficult for an individual. WFC has emerged as an important issue today (Burke \& El-Kot, 2010) and of special interest for national and international scholars regarding the attitudes of employees towards work and the workplace (Gutek et al., 1991; Higgins \& Duxbury, 1992). WFC negatively affects behavior, emotions, and health and its impact tend to be greatly underestimated. As time and resources are limited, fulfilling diverse roles for the 
individual causes tiredness, greater stress, performance loss, lowering of work satisfaction, and organizational commitment (Magnus \& Viswesvaran, 2004). Due to the difficulties in fulfilling multiple responsibilities, balancing work and family has become the biggest challenge in an adult's life (Byron, 2005). In this regard, several studies have been done in the individualistic societies of the developed world, but little work has been done in the collectivist societies in the developing world (Baral \&Bhargava 2010).

In modern economies of the developing world, the demographic changes have resulted in a shift in the traditional single-earner families to dual-earner families (Premeaux et al., 2007; Shockley et al., 2017). Working women consistently feel under pressure while integrating work roles and responsibilities at home (Grady \& McCarthy, 2008; Shockley et al., 2017). In Pakistan, WFC has emerged as an established issue, representing a collectivist culture. The family responsibilities of women at home go beyond the nuclear family (spouse and children) to include ensuring the wellbeing of elders (parents and in-laws) as well. As such, the impact of this conflict is overwhelming for the female workforce in Pakistan.

\section{Research Questions}

1. Does WFC have any impact on job satisfaction?

2. Is there any influence of WFC on life satisfaction?

3. Is there any impact of job satisfaction on life satisfaction?

\section{Literature Review}

The theoretical paradigm of WFC and the work/life balance can be understood in light of Role Conflict Theory (Greenhaus \& Beutell, 1985) which argues that conflict is perceived to exist when the role of an individual in one domain (work) is incompatible and restricts the performance of the other role (family) (Burke \& El-Kot, 2010). WFC is experienced when the demands of work - long working hours, inflexible work schedule, and unsupportive workplace culture interferes with family obligations. In a similar vein, persistent conflict occurs when the demands of housecare, child and elderly care along with lack of social support interfere with the demands at work. 
According to Greenhaus and Beutell (1985), the theory identifies three dimensions of the conflict. The first one is the time-based conflict when one role demands more time and less time is left for participation in the other role. The time required for work can be working hours on the job, commuting time, overtime, and shift time whereas the time required for the family is the time needed for performing tasks at home which is influenced by marital status, size of the family, children and dependent parents, and lack of social support. Second, strain-based conflict occurs when stress, fatigue caused in doing the role of one domain affects the work of the other role. Lastly, the behavior-based conflict occurs when performance in the two domains are not compatible, e.g. expressiveness, being emotional, and sensitivity is mannerisms for family and is considered dysfunctional for the workplace (Carlson et al., 2000; Parasuraman \& Greenhaus, 1992).

Various scholars have defined job satisfaction as an emotional response to the actual outcome versus the desired outcome from work (Cranny et al 1992). Locke (1969) explains job satisfaction as an emotional state based on evaluating the job. Kim and Ling (2001) elucidate it as an emotional response whereas Brief (1998) defines job satisfaction as an attitude towards one's job. These definitions cover the emotional state of the individual, which not only affects one's responses to work but also formulates his/her perception of the work (Alonso, 2006).

The study of past researches sees these two definitions of feeling and attitude as synonymous and not inconsistent (Locke, 1976; Smith, 1969). The result of the conflict can cause burn-out and related issues i.e., lack of personal accomplishment, lower level of psychological wellbeing and emotional exhaustion (Smith et al., 2018), loss of meaningfulness (Chalofsky, 2003), as well as negatively affect work performance, and reduced job satisfaction (Mackey et al., 2002). Another study (Greenhaus et al., 2006) identifies Work-Family conflict with diminished value attainment, which in turn relates to low levels of job satisfaction. Huang (2004) noted that the conflict not only lowers one's level of satisfaction from work, but also causes absenteeism, tiredness at work, and generates a desire to change jobs. If family responsibilities restrict time and energy for the accomplishment of a given task on the job, there arises a conflict that lowers job satisfaction (Frone, 2003; Greenhaus et al., 2006). Boles (2001) found similar outcomes where work and family conflict negatively impacts job satisfaction, though a wide range of studies also relates work and family conflict to a low level of job satisfaction. Nevertheless, 
Namasivayam (2004) argued that family interference with work can be both positive and negative. Therefore, the impact of WFC on job satisfaction can vary according to different cultural backgrounds also.

Life satisfaction refers to an individual's cognitive assessment of circumstances of his life with researchers making the case that circumstances in the two domains of job and family form an impact on life satisfaction (Erdogan et al., 2012). Since life satisfaction covers a wide range of activities of daily routine, conflict in work and non-work domains disrupt emotions (Kim \& Ling 2001). Arora (1990) reported that WFC and life satisfaction are negatively related, whereas Cooke and Rousseau (1984) found that stress between the two domains of family and work not only lowers job satisfaction but also creates life dissatisfaction.

This is reported especially for 'dual-career couples' where both husband and wife are working (Greenhaus, 1983; Holahan \& Gilbert, 1979; Pleck, 1980) and have lower levels of satisfaction with their lives. Studies done of organizational variables (Schaufeli \& Enzmann, 1998; Smith et al., 2018) confirm that work overload, meeting deadlines, and role conflict at work, rather than interaction with clients, causes emotional exhaustion and lowers life satisfaction. Sirgy and Lee (2018) argued that role conflict in performing the responsibilities at work and in the family contributes to lowering both job and life satisfaction.

There are competing theories for understanding the relationship between job satisfaction and life satisfaction, based upon the two concepts of segmentation and spillover. The segmentation concept argument is that an individual, unintentional or intentional tends to make an active adjustment to separate work and non-work domains of life (Dubin, 1956, 1973; Seeman, 1967; Wilensky, 1960). This is done to manage stress in such a way that pressure in one area does not affect the other domain. The spillover concept is based on the theory that suggests a consistent positive relationship between job satisfaction and life satisfaction (Lane \& Steiner, 1991).

\section{Hypotheses}

Based upon our literature review, the following hypotheses were developed:

H1. There is a definite impact of WFC on job satisfaction. 
H2. WFC affects life satisfaction.

H3. Job satisfaction affects life satisfaction.

\section{Methodology}

\section{Research Design}

The study follows the quantitative research design and was conducted using an 18 item questionnaire developed by Carlson et al. (2000) with permission taken from the authors. Questions were asked on three dimensions identified by the role conflict theory: time-based conflict, strain-based conflict, and behavior-based conflict.

\section{Participants}

Participants in the proposed study included a random sample of 200 female Executive MBA students from four universities. Demographics of the survey show $91.2 \%$ of respondents were $25-35$ years of age, $6 \%$ were of $36-45$ years and $2.8 \%$ were above 45 years. Regarding marital status, $75 \%$ were married and $21.8 \%$ were unmarried, while $2.8 \%$ were single, divorced, or separated. In family size, $86 \%$ had no children, while the rest had one or more children. Of the participants with family, $6.5 \%$ had one offspring while $2.8 \%$ had three. Around $43 \%$ of the respondents lived in joint families, while $56.9 \%$ lived in nucleus families. Since the present study is interested in examining graduate students who experience work-family conflict, the base level education is a Bachelors Degree.

\section{Instrument}

The 18 item questionnaire developed by Carlson et al., (2000) has been used for measuring multidimensional WFC (time-based, strain-based, and behaviorbased). A sample of the type of questions asked included 'my work keeps me from my family activities more than I would like and so forth. The responses range from 1) strongly disagree, 2) slightly disagree, 3) impartial, 4) slightly agree, and 5) strongly agree. The Cronbach alpha of the WFC scale was .85.

\section{Data Analysis}

To measure life satisfaction, the scale prepared 5 items which were constructed by Diener et al., (1985) and used in the survey. A 7-point Likert scale 
was used to measure responses, while the Cronbach alpha of the SWL scale was .87 .

To measure job satisfaction 6 items were selected from the 18-item index developed by Brayfield and Rothe (1951) was taken, the validity and reliability of which has been established through its usage in time. A 5- point scale was used to measure the responses, while the Cronbach alpha of the JSI scale was .95. The data collected were analyzed using the Statistical Package for Social Sciences (SPSS) version 24.

\section{Findings}

The results for question 1, 'Does WFC have any impact on job satisfaction and of hypothesis one i.e. WFC will impact job satisfaction is shown in Table 1 that the regression model predicts job satisfaction as insignificant, $\mathrm{P} \geq 0.0005$ which is more than 0.05 and indicates that, overall, the model applied is insignificant in predicting the outcome variable. Table 3 provides the $\mathrm{R}$ and $\mathrm{R}^{2}$ values. The $\mathrm{R}$-value is .011, which represents no correlation. The $\mathrm{R}^{2}$ value indicates how much of the dependent variable, job satisfaction, can be explained by the independent variable, WFC.

The results for question 2, 'Is there any influence of WFC on life satisfaction?' and hypothesis two i.e. life satisfaction is influenced by WFC are shown in Table 4. It shows that the regression model predicts the dependent variable as life satisfaction which is insignificant, $\mathrm{P} \geq 0.0005$ which is more than 0.05 , and indicates that, overall, the model applied is insignificant in predicting the outcome variable. Table 6 provides the $\mathrm{R}$ and $\mathrm{R}^{2}$ values. The $\mathrm{R}$-value is .10 , which represents a weak correlation. The $\mathrm{R}^{2}$ value indicates how much of the dependent variable, WFC, can be explained by the independent variable (life satisfaction).

The results of question 3, 'Is there an impact of job satisfaction on life satisfaction?' and of hypothesis three i.e. life satisfaction is influenced by job satisfaction is shown in Table 7 which shows that the regression model predicts the dependent variable insignificantly, $\mathrm{P} \geq 0.0005$ which is more than 0.05 and indicates that, overall, the model applied is insignificant in predicting the dependent variable. Table 9 provides the $R$ and $R^{2}$ values, whereas the $R$-value is .106 , which represents no correlation. The $\mathrm{R}^{2}$ value indicates how much of the dependent variable (job satisfaction) can be explained by the independent variable (life satisfaction). 
Work-Family Conflict, Job and Life Satisfaction

\section{Table 1}

Analysis of Variance for Linear Regression with Work-FamilyConflict as a predictor of Job Satisfaction

\begin{tabular}{llccccc}
\hline Model & & SS & Df & MS & F & Sig \\
\hline 1 & Regression & .460 & 1 & .460 & .024 & $.876 \mathrm{a}$ \\
& Residual & 3744.160 & 198 & 18.910 & & \\
& Total & 3744.620 & 199 & & & \\
\hline
\end{tabular}

a. Predictors: (Constant), Work-FamilyConflict

b. Dependent Variable: Job Satisfaction

\section{Table 2}

Coefficients for Linear Regression with Work-FamilyConflict as a predictor of Job Satisfaction

\begin{tabular}{llccccc}
\hline \multirow{2}{*}{ Model } & & \multicolumn{2}{c}{$\begin{array}{c}\text { Unstandardized } \\
\text { Coefficients }\end{array}$} & $\begin{array}{c}\text { Standardized } \\
\text { Coefficients }\end{array}$ & \multirow{2}{*}{ t } & \multirow{2}{*}{ Sig. } \\
\cline { 3 - 5 } & & B & Std. Error & Beta & & \\
\hline 1. & (Constant) & 19.847 & 1.423 & & 13.951 & .000 \\
& Work-Family Conflict & -.004 & 0.27 & -0.11 & -.156 & .876 \\
\hline
\end{tabular}

a. Dependent Variable: Job Satisfaction

\section{Table 3}

Summary of Linear Regression with Work-FamilyConflict as a predictor of Job Satisfaction

\begin{tabular}{lccc}
\hline Model & $\mathbf{R}$ & $\mathbf{R}^{\mathbf{2}}$ & Adjusted $\mathbf{R}^{\mathbf{2}}$ \\
\hline 1 & $.011^{\mathrm{a}}$ & .000 & -.005 \\
\hline
\end{tabular}

\section{Table 4}

Analysis of Variance for Linear Regression with Life Satisfaction as a predictor of Work-Family Conflict

\begin{tabular}{llccccc}
\hline Model & & SS & Df & MS & F & Sig \\
\hline 1 & Regression & 254.655 & 1 & 254.655 & 1.987 & $.160 \mathrm{a}$ \\
& Residual & 25379.425 & 198 & 128.179 & & \\
& Total & 25634.080 & 199 & & & \\
\hline
\end{tabular}

a. Predictors: (Constant), Life Satisfaction

b. Dependent Variable: Work-Family Conflict 


\section{Table 5}

Coefficients for Linear Regression with Life Satisfaction as a predictor of WorkFamily Conflict

\begin{tabular}{llccccc}
\hline \multirow{2}{*}{ Model } & & \multicolumn{2}{c}{$\begin{array}{c}\text { Unstandardized } \\
\text { Coefficients }\end{array}$} & $\begin{array}{c}\text { Standardized } \\
\text { Coefficients }\end{array}$ & \multirow{2}{*}{ t } & \multirow{2}{*}{ Sig. } \\
\cline { 3 - 5 } & & B & Std. Error & Beta & & \\
\hline 1. & (Constant) & 47.564 & 2.660 & & 17.880 & .000 \\
& Life Satisfaction & .207 & .147 & .100 & 1.410 & .160 \\
\hline
\end{tabular}

a. Dependent Variable: Work-Family Conflict

\section{Table 6}

Summary of Linear Regression with Life Satisfaction as a predictor of Work-Family Conflict

\begin{tabular}{lccc}
\hline Model & $\mathbf{R}$ & $\mathbf{R}^{\mathbf{2}}$ & Adjusted $\mathbf{R}^{\mathbf{2}}$ \\
\hline 1 & $.100^{\mathrm{a}}$ & .010 & .005 \\
\hline
\end{tabular}

\section{Table 7}

Analysis of Variance for Linear Regression with Life Satisfaction as a Predictor of Job Satisfaction

\begin{tabular}{llccccc}
\hline Model & & SS & Df & MS & F & Sig \\
\hline 1 & Regression & 42.001 & 1 & 42.001 & 2.246 & $.136 \mathrm{a}$ \\
& Residual & 3702.619 & 198 & 18.700 & & \\
& Total & 3744.620 & 199 & & & \\
\end{tabular}

a. Predictors: (Constant), Life Satisfaction

b. Dependent Variable: Job Satisfaction

\section{Table 8}

Coefficients for Linear Regression with Life Satisfaction as a Predictor of Job Satisfaction

\begin{tabular}{llccccc}
\hline \multirow{2}{*}{ Model } & & \multicolumn{2}{c}{$\begin{array}{c}\text { Unstandardized } \\
\text { Coefficients }\end{array}$} & $\begin{array}{c}\text { Standardized } \\
\text { Coefficients }\end{array}$ & \multirow{2}{*}{ t } & \multirow{2}{*}{ Sig. } \\
\cline { 3 - 5 } & & $\mathbf{B}$ & Std. Error & Beta & & \\
\hline 1. & (Constant) & 21.082 & 1.016 & & 20.749 & .000 \\
& Life Satisfaction & -.084 & .056 & -1.06 & -1.499 & .136 \\
\hline
\end{tabular}

a. Dependent Variable: Job Satisfaction 


\section{Table 9}

Summary of Linear Regression with Life Satisfaction as a Predictor of Job Satisfaction

\begin{tabular}{lccc}
\hline Model & $\mathbf{R}$ & $\mathbf{R}^{2}$ & Adjusted $\mathbf{R}^{2}$ \\
\hline 1 & $.106^{\mathrm{a}}$ & .011 & .006 \\
\hline
\end{tabular}

\section{Discussion}

The findings for Question 1 and Hypothesis 1 that examines the impact of WFC on job satisfaction, the results were supported by the previous study conducted in public sector universities of Pakistan, which stated a negative and insignificant relation between WFC and job satisfaction (Waheed, 2014). Similarly, the studies by (Boles, 2001; French et al., 2018; Kossek \& Ozeki, 1998) indicate insignificant relation between WFC and job satisfaction. In contrast, mixed results are shown by some other studies (Bedeian, 1988; Carlson \& Kacmar, 2000, Netemeyer, 2004), no significant impact by O'Driscoll (1992), and low significant relationship by Noor (2004). The study on social workers (Parveen \& Thomas, 2015) showed that the time and strain conflict from work to family reduces job satisfaction, whereas behavior as a variable can create conflict from family to work and can be a predictor of reduced job satisfaction. This issue shows a wide range of WFC impacts has on job satisfaction due to the varied contexts and demographics.

For question 2 and Hypothesis 2, which sought to understand the effect of WFC on life satisfaction, the results showed an insignificant in predicting the outcome variable. Continuing with the phenomenon, the study done in the Pakistani banking sector indicates that the pay scale is a strong indicator in job satisfaction than WFC (Maqsood et al., 2014). In large cities like Karachi, where issues such as unemployment, inflation, and uncertain conditions exist, having a regular job leads to satisfaction in life. On the other hand, the inter- role stress and strain in domains of family and work leading to lower job satisfaction (hypothesis 1) and also life satisfaction (hypothesis 2), especially in dual-career families are manifested for both males and females (Holahan \& Gilbert, 1979; Pleck, 1980; Greenhaus, 1983) as mentioned in the literature review. In studies conducted by Lu et al., (2005, 2008) it was established that WFC does not reflect in lack of job satisfaction and overall happiness. 
The results of a study by Zhao et al., (2009) in the hotel business explained that Human Resource policies adopted to reduce the stress caused by WFC, result in causing an insignificant impact. The study was done by Treistman (2004) on WFC and life satisfaction in female graduate students documented the very little impact of WFC on life satisfaction. This study supports question 2 and hypothesis 2 and perceives that social support is a positive predictor of global life satisfaction in furtherance of question 3 and hypothesis 3 which focuses upon the effects of job satisfaction on life satisfaction.

A possible explanation of the findings is that demographic structure can be playing a strong role because the present study covered $91 \%$ of the sample between the age of 25-35years. These women were largely young and educated, 75\% of whom were unmarried and $43 \%$ of whom lived in joint families. The data was collected in private sector universities and therefore depicting that they belonged to the upper-middle and the elite segment of the society. These women are largely living with their parents and as such being daughters from upper-middle and elite eastern culture households are often pampered. There are no demands for household chores since household help is in abundance and therefore there is no inter-role stress on the sampled women. The younger age sample means younger parents, because of early marriages in Pakistan, and can also provide adequate support for their children. Similar to Treistman (2004) suggestions that because of social support, WFC does not impact adversely on job and life satisfaction. The different results can also be attributed to the fact that the data is collected from individuals, whereas WFC is a dynamic process evolving in nuclear families as the interaction between two people, therefore different results may come from the study of couples as a unit (Hammer et al., 1997).

Since stress is cumulative from many sources, the source of stress may be an individual's interpretation and not real according to attribution theory. The relationship between job satisfaction and WFC also depends on the motivational structure of an individual as his or her priorities are either on their career or family (Smith et al., 2018). Lobell (1992) felt that if values at home and workplace are similar, the stress is less, whereas Karasaek and Theorell, (1990) take into consideration that the taking up of a career maybe by choice which eventually reduces stress. Stress level varies if the individual is forced into doing the work, putting in extra hours based on financial needs, or doing it because he or she enjoys 
doing it (Smith et al., 2018). Pakistan is a traditional society where there is a strong perception that the male is the 'breadwinner'. This perceived notion of 'man being the provider' means that a male is there to offer support to a female worker in an office setting, with the result that his value structure downplays female stress (Shockley et al., 2017).

Although a large body of research exists on WFC experienced by people working in the paid labor force while simultaneously doing full-time family roles as homemakers; however, there is a lack of research that examines the unique population of female executive graduate students and their WFC experiences which this research tried to fill. Research in the future can be enlarged to include the relationship between WFC and self-efficacy. The results can then be used to understand the relationship between WFC and work satisfaction and form a guide for employer's policies. Future research should continue to examine additional variables, as well as larger samples of racial and ethnic minority groups of female graduate students.

\section{Conclusions and Recommendations}

There was seen to be no impact of WFC on job satisfaction and life satisfaction and job satisfaction does not affect life satisfaction concerning female MBA Executive students studying at the Private business schools of Pakistan. The discussion of the results shows that social support is a variable that is different in various cultures. In traditional societies like Pakistan, we can consider grandparents, relatives, neighbors, nannies, and other household staff who can perform a major part of the domestic tasks and therefore reduce WFC. It can be thus implied that one's economic standing and social support play a great role in work-family conflict. Nevertheless, more research needs to be conducted with a larger sample size and more closed sample characteristics to come to any definite conclusion.

\section{References}

Baral, R., \& Bhargava, S. (2010). Work-family enrichment as a mediator between organizational interventions for work-life balance and job outcomes. Journal of Managerial Psychology, 25(3), 274-300.

Bedeian, A. G., Burke, B. G., \& Moffett, R. G. (1988). Outcomes of work-family conflict among married male and female professionals. Journal of Management, 14(3), 
475-491.

Boles, J. S., Howard, W. G., \& Donofrio, H. H. (2001). An investigation into the interrelationships of work-family conflict, family-work conflict and work satisfaction. Journal of Managerial Issues, 13, 376-390.

Brayfield, A. H., \& Rothe, H. F. (1951). An index of job satisfaction. Journal of Applied Psychology, 35, 307-311. doi:10.1037/h0055617

Brief, A. P. (1998). Attitudes in and around organizations (Vol. 9). Sage.

Burke, R. J., \& El-Kot, G. (2010). Correlates of work-family conflicts among managers in Egypt. International Journal of Islamic and Middle Eastern Finance and Management, 3(2), 113-131.

Carlson, D. S., \& Kacmar, K. M. (2000). Work-family conflict in the organization: Do life role values make a difference?. Journal of Management, 26(5), 1031-1054.

Chalofsky, N. (2003). An emerging construct for meaningful work. Human Resource Development International, 6(1), 69-83.

Cooke, R. A., \& Rousseau, D. M. (1984). Stress and strain from family roles and work-role expectations. Journal of Applied Psychology, 69(2), 252.

Cranny, C.J., Smith, P.C. and Stone, E.F. (1992)'The construct of job satisfaction', in C.J. Cranny, P.C. Smith and E.F. Stone (eds), Job satisfaction: Howpeople feel about their jobs and how it affects their performance.Lexington Books.

Dubin, R. (1956). Industrial workers' worlds: A study of the "central life interests" of industrial workers. Social Problems, 3(3), 131-142.

Erdogan, B., Bauer, T. N., Truxillo, D. M., \& Mansfield, L. R. (2012). Whistle while you work: A review of the life satisfaction literature. Journal of Management, 38(4), 1038-1083.

French, K. A., Dumani, S., Allen, T. D., \& Shockley, K. M. (2018). A meta-analysis of work-family conflict and social support. Psychological Bulletin, 144(3), 284.

Grady, G., \& McCarthy, A. M. (2008). Work-life integration: Experiences of mid-career professional working mothers. Journal of Managerial Psychology, 23(5), 599-622.

Greenhaus, J. H., \& Beutell, N. J. (1985). Sources of conflict between work and family roles. Academy of Management Review, 10(1), 76-88.

Greenhaus, J. H., Allen, T. D., \& Spector, P. E. (2006). Health consequences of workfamily conflict: The dark side of the work-family interface. In Employee health, coping and methodologies. Emerald Group Publishing Limited.

Hammer, L. B., Allen, E., \& Grigsby, T. D. (1997). Work-family conflict in dual-earner couples: Within-individual and crossover effects of work and family. Journal of Vocational Behavior, 50(2), 185-203. 
Higgins, C. A., \& Duxbury, L. E. (1992). Work—family conflict: A comparison of dualcareer and traditional-career men. Journal of Organizational Behavior, 13(4), 389411.

Holahan, C. K., \& Gilbert, L. A. (1979). Interrole conflict for working women: careers versus jobs. Journal of Applied Psychology, 64(1), 86.

Huang, X., \& Vliert, E. V. D. (2004). Job level and national culture as joint roots of job satisfaction. Applied Psychology, 53(3), 329-348.

Kalliath, P., \& Kalliath, T. (2013). Work-family conflict and its impact on job satisfaction of social workers. British Journal of Social Work, 45(1), 241-259.

Kossek, E. E., \& Ozeki, C. (1999). Bridging the work-family policy and productivity gap: A literature review. Community, Work \& Family, 2(1), 7-32.

Lobel, S. A., \& Clair, L. S. (1992). Effects of family responsibilities, gender, and career identity salience on performance outcomes. Academy of Management Journal, 35(5), 1057-1069.

Locke, E. A. (1969). What is job satisfaction?. Organizational Behavior and Human Performance, 4(4), 309-336.

Locke, E. A. (1976). The nature and causes of job satisfaction. In M. D. Dunnette (Ed.),Handbook of industrial and organizational psychology (pp. 1297-1349). Rand-McNally.

Mackey Jones, W., \& McKenna, J. (2002). Women and work-home conflict: A dual paradigm approach. Health Education, 102(5), 249-259.

Mesmer-Magnus, J. R., \& Viswesvaran, C. (2005). Convergence between measures of work-tofamily and family-to-work conflict: A meta-analytic examination. Journal of Vocational Behavior, 67(2), 215-232.

Namasivayam, K., \& Zhao, X. (2007). An investigation of the moderating effects of organizational commitment on the relationships between work-family conflict and job satisfaction among hospitality employees in India. Tourism Management, 28(5), 1212-1223.

Netemeyer, R. G., Brashear-Alejandro, T., \& Boles, J. S. (2004). A cross-national model of jobrelated outcomes of work role and family role variables: A retail sales context. Journal of the Academy of marketing Science, 32(1), 49-60.

Noor, S., \& Maad, N. (2009). Examining the relationship between work life conflict, stress and turnover intentions among marketing executives in Pakistan. International Journal of Business and Management, 3(11), 93.

O'Driscoll, M. P., Ilgen, D. R., \& Hildreth, K. (1992). Time devoted to job and offjob activities, interrole conflict, and affective experiences. Journal of Applied 
Psychology, 77(3), 272.

Parasuraman, S., Greenhaus, J. H., \& Granrose, C. S. (1992). Role stressors, social support, and well-being among two-career couples. Journal of Organizational Behavior, 13(4), 339-356.

Pleck, J. H. (1977). The work-family role system. Social Problems, 24(4), 417-427.

public sector universities of Pakistan. Conference Proceedings of the ICCBM (pp. 1-28).

Schaufeli, W.B., \& Enzmann, D. (1998). The burnout companion to study and practice: A critical analysis. Taylor \& Francis.

Seeman, M. (1967). On the personal consequences of alienation in work. American Sociological Review, 32, 273-285.

Shockley, K. M., Shen, W., DeNunzio, M. M., Arvan, M. L., \& Knudsen, E. A. (2017). Disentangling the relationship between gender and work-family conflict: An integration of theoretical perspectives using meta-analytic methods. Journal of Applied Psychology, 102(12), 1601.

Sirgy, M. J., \& Lee, D. J. (2018). Work-life balance: An integrative review. Applied Research in Quality of Life, 13(1), 229-254.

Smith, P. C., Kendall, L., \& Hulin, C. L. (1969). The measurement of satisfaction in work and retirement. Rand McNally.

Smith, Todd D., Kevin Hughes, David M. DeJoy, and Mari-Amanda Dyal. (2018). Assessment of relationships between work stress, work-family conflict, burnout and firefighter safety behavior outcomes. Safety Science, 103, 287-292.

Treistman, D.L. 2004. Work-family conflict and life satisfaction in female graduate students: Testing mediating and moderating hypotheses. (Unpublished doctoral dissertation), University of Maryland.

Waheed, M. H. (2014) Impact of work-family conflicts on job satisfaction, organizational commitment and intentions to turnover among faculty members: A perspective of

Wilensky, H. L. (1960). Work, careers and social integration. International Social Science Journal, 12(4), 543-560.

Zhao, X., \& Qu, H. (2009, August). A study on the impacts of work-family conflict on job and life satisfaction among hotel sales managers in China. In International CHRIE Conference Refereed Track (p. 2). 